\title{
HOPPING CONDUCTION MECHANISM IN AMORPHOUS $\mathrm{CuO}-\mathrm{Bi}_{2} \mathrm{O}_{3}$ PELLETS
}

\author{
S.G. MoTKE \\ Department of Physics, B.N. College of Engineering \\ Pusad, Dist-Yavatmal, 445 215, India \\ D.K. Burghate \\ Department of Physics, Shri Shivaji Science College, Amravati, India \\ W.J. Gawande, S.V. Pakade and S.P. Yawale \\ Material Research Laboratory, Department of Physics, Govt. Vidarbha Mahavidyalaya \\ Amravati, 444 604, India \\ (Received October 4, 1993; revised version June 6, 1994)

\begin{abstract}
The transport properties of $\mathrm{CuO}-\mathrm{Bi}_{2} \mathrm{O}_{3}$ pellets (pressed at room temperature $303 \mathrm{~K}$ ) like dc electrical conductivity etc. are measured. The activation energy, dielectric constant etc. are reported. The hopping conduction is examined. Non-adiabatic hopping conduction is observed. The plot of $-\log \sigma$ versus $1 / T$ is found to be linear. Activation energy of pellets containing $\mathrm{CuO}$ $(80,70,60 \mathrm{~mol} \%)$ shows electronic conduction while the pellet containing $\mathrm{CuO}(50 \mathrm{~mol} \%)$ shows ionic conduction. The effect of content of $\mathrm{CuO}(\mathrm{mol} \%)$ and frequency on dielectric constant is also studied. The variation of dielectric constant with $\mathrm{CuO}(\mathrm{mol} \%)$ shows zigzag nature and may be due to the relaxation effects.
\end{abstract}

PACS numbers: $72.80 . \mathrm{Ng}, 72.90 .+\mathrm{y}$

\section{Introduction}

Oxide glasses have been traditionally used as insulators. In order to find out the nature of conductivity (ionic or electronic) investigation was performed by research workers in oxide glasses. Firstly, Denton et al. [1] observed the electronic conduction in oxide glasses in 1954. Study of oxide glass systems showing semiconducting behaviour has been done by many research workers [2-4]. Nowadays computer memories might be cheaply produced from oxide glasses containing fine bismuth particles, exhibiting memory switching. The transport properties of semiconducting glasses gives information about the conduction mechanism. The 
dc conductivity measurement in the temperature range 300-500 $\mathrm{K}$ of vanadium bismuth oxide glasses has been done by Ghosh et al. [5]. They observed adiabatic hopping conduction. Similarly the dc conductivity of sodium cuprous phosphate glasses having different cuprous ion concentration has been measured by Singh et al. [6] in the range $80-490 \mathrm{~K}$ and the possibility of ionic or electronic conduction has been discussed.

Authors of Refs. $[7,8]$ have recently studied dc conductivity and hopping conduction mechanism in $\mathrm{CuO}-\mathrm{Bi}_{2} \mathrm{O}_{3}$ amorphous pellets pressed at temperatures $323 \mathrm{~K}$ and $373 \mathrm{~K}$. Similarly, a comparative study of these pellets with glass sample is also done [9]. The electrical conductivity of most of glasses has been studied by many research workers but less attention has been given to the pellets of glass powder. Therefore, we decided to study various transport properties of $\mathrm{CuO}-\mathrm{Bi}_{2} \mathrm{O}_{3}$ pellets with intention to know the behaviour of conduction mechanism. In the present work measurement has been done of dc conductivity of $\mathrm{CuO}-\mathrm{Bi}_{2} \mathrm{O}_{3}$ pellets having different concentrations of both compounds in the temperature range 305 to $623 \mathrm{~K}$. Similarly, the variation of dielectric constant with frequency and content of $\mathrm{CuO}(\mathrm{mol} \%)$ is studied. The possibility of ionic and/or electronic conduction in the pellets is discussed.

\section{Experimental details}

\subsection{Sample preparation}

The pellets were prepared by weighing Anala- $\mathrm{R}$ grade chemicals (powder form) of $\mathrm{CuO}-\mathrm{Bi}_{2} \mathrm{O}_{3}$ in appropriate amount (mol\%) on K-Roy monopan balance having accuracy of $\pm 0.00001 \mathrm{mg}$. The homogeneity of mixture was affected by repeated grinding. The mixture was fired in fireclay crucible at $1200^{\circ} \mathrm{C} \pm 10^{\circ} \mathrm{C}$ for two hours in an automatically temperature controlled muffle furnace. The molten masses were allowed to cool at room temperature $(303 \mathrm{~K})$ and then crushed. The pellets were prepared by pressing powder isostatically in suitable stainless steel die having pressure of 2 tons $/ \mathrm{cm}^{2}$ with binding reagent euprol at room temperature $(303 \mathrm{~K})$. The pellets were polished to smooth surfaces and to a thickness of $2 \mathrm{~mm}$ using fine quality emery paper. After application of conductive silver paint, pellets were used for electrical measurements. The amorphous nature of sample was checked by X-ray diffraction method.

\subsection{Electrical measurement}

The voltage drop method given by Kher et al. [10] and Yawale [11] was used to measure the resistance of pellets. The voltage across the standard resistance was determined by digital voltmeter DT-850 (Japan) having accuracy $\pm 0.1 \mathrm{mV}$. The resistance of pellets of different compositions was measured at constant voltage $(600 \mathrm{~V})$. Readings were taken at various temperatures. The measurement of capacity of pellets was done using Radart LCR bridge 5102 in the frequency range of $20 \mathrm{~Hz}$ to $20 \mathrm{kHz}$ at room temperature (303 K). 


\section{Theory}

In ionic conduction, ionic species overcome the barrier $W$ and contribute to electrical conduction; basing on this assumptions, Stevels [12] has derived resistivity equation

$$
\rho=\frac{6 k T}{\eta \nu S \xi Z^{2} e^{2}} \exp \left(\frac{W}{k T}\right),
$$

where $\eta$ is the concentration of mobile ions, $Z e$ is the charge on ion, $k$ is the Boltzman constant, $\nu$ is the vibrational frequency of ion, $\xi$ is the average distance between the two sites over which jump occurs, $S$ is the number of available alternate sites to which mobile ion may jump. The expression given by Stevels [12] for resistivity is modified and simple expression for ionic conductivity is derived by Elliot [13]. Assuming that ionic motion occurs by filled enhanced thermally activated hopping between equivalent sites in the lattice, the ionic conductivity is given by the following expression:

$$
\sigma=\frac{N e^{2} R^{2} \nu}{k T} \exp \left(\frac{-W}{k T}\right)
$$

where $N$ is the number of available ions per unit volume, $\nu$ is the vibrational frequency for an atom constrained in the potential well at a site, $e$ is the charge of ion, $R$ is the site spacing. According to Elliot [13], if the plot of $-\log (\sigma T)$ versus $1 / T$ is linear, the ionic conduction is dominant. Considering non-adiabatic approximation the $\mathrm{dc}$ conductivity of semiconducting oxide glasses has been expressed as $[4,14]$ :

$$
\sigma=\frac{\nu N e^{2} R^{2}}{k T} C(1-C) \exp (-2 \alpha R) \exp \left(\frac{-W}{k T}\right),
$$

where $\alpha$ is the electron wave function decay constant, $C$ is the mole fraction of sites occupied by electron, $W$ is the activation energy arising from the electron-lattice interaction.

Assuming that a strong electron-lattice interaction exists, activation energy $(W)$ is the result of polaron formation with binding energy $\left(W_{\mathrm{p}}\right)$ and any energy difference $\left(W_{\mathrm{D}}\right)$ which might exist between the initial and final sites due to variation of the local arrangement of ions. It can be expressed as $[4,14]$ :

$$
\begin{aligned}
W & =W_{\mathrm{H}}+\frac{W_{\mathrm{D}}}{2} & \text { for } & T>\frac{\Theta_{\mathrm{D}}}{2}, \\
& =W_{\mathrm{D}} & \text { for } & T<\frac{\Theta_{\mathrm{D}}}{4}
\end{aligned}
$$

where $W_{\mathrm{H}}$ is the polaron hopping energy, $\Theta_{\mathrm{D}}$ is the Debye temperature, $W_{\mathrm{D}}$ is the disorder energy arising from the energy difference between two neighbouring hopping sites. The polaron hopping energy $W_{\mathbf{H}}$ is given by

$$
W_{\mathrm{H}}=\frac{W_{\mathrm{p}}}{2}
$$

and $W_{\mathrm{p}}$ is the polaron binding energy. $W_{\mathrm{H}}$ is also expressed as

$$
W_{\mathrm{H}}=\frac{e^{2}}{4 \varepsilon_{\mathrm{p}}}\left(\frac{1}{r_{\mathrm{p}}}-\frac{1}{R}\right) \text {, }
$$


where

$$
\frac{1}{\varepsilon_{\mathrm{p}}}=\frac{1}{\varepsilon_{\infty}}-\frac{1}{\varepsilon_{\mathrm{s}}}
$$

and $\varepsilon_{\mathrm{s}}$ and $\varepsilon_{\infty}$ are static and high frequency dielectric constants of the sample, respectively and $\varepsilon_{\mathrm{p}}$ is an effective dielectric constant.

The polaron radius $\left(r_{\mathrm{p}}\right)$, which is estimated from site spacing $(R)$, is given by

$$
r_{\mathrm{p}}=\frac{1}{2}\left(\frac{\pi}{6 N}\right)^{1 / 3}=\frac{R}{2}\left(\frac{\pi}{6}\right)^{1 / 3}
$$

Further Holstein [15] expressed polaron binding energy $\left(W_{\mathrm{p}}\right)$

$$
W_{\mathrm{p}}=\frac{1}{2 N^{\prime}} \sum_{q^{\prime}}\left|\nu_{q^{\prime}}\right|^{2} \hbar W_{q^{\prime}}
$$

where $\left|\nu_{q^{\prime}}\right|^{2}$ is the electron-phonon coupling constant, $W_{q^{\prime}}$ is the frequency of optical phonons of wave number $q^{\prime}, N^{\prime}$ is the site density.

In order to check the adiabatic and/or non-adiabatic hopping conduction various methods have been suggested by many research workers [15, 16]. However, the method suggested by Murawaski et al. [18] and Sayer et al. [17] is adopted, when overlap integral between sites $J_{0} \exp (-\alpha R) \rightarrow J_{0}$, i.e. $\exp (-2 \alpha R) \rightarrow 1$, indicates adiabatic hopping and is mainly controlled by activation energy. Therefore Eq. (3) reduces to

$$
\sigma=\frac{\nu N e^{2} R^{2}}{k T} C(1-C) \exp \left(\frac{-W}{k T}\right) .
$$

To explore the nature of hopping conduction, a dependence of $-\log \sigma$ versus activation energy $(W)$ at fixed temperature for samples of different composition is to be plotted. If this plot shows straight line nature, then it indicates that Eq. (10) is valid. This plot gives the slope equal to $1 / k T$ and intercept on $-\log \sigma$ axes gives the value of constant $A$

$$
A=\log \left(\frac{\nu N e^{2} R^{2}}{k T}\right) C(1-C) .
$$

From the slope $1 / k T$, the value of temperature is estimated. If the estimated temperature is found to be nearly equal to chosen temperature (in $\mathrm{K}$ ), then the hopping conduction is adiabatic in nature. If $\mathrm{Eq}$. (10) is not valid, the value of estimated temperature from the plot and the chosen fixed temperature will be very different. This suggests that the nature of hopping conduction is non-adiabatic.

\section{Results and discussion}

The variation of $-\log$ of electrical conductivity $(\sigma)$ with $1 / T$ is plotted (Fig. 1). dc conductivity exhibits a linear relationship throughout the temperature range for all pellets. This suggests that the activation energy is temperature independent. It is observed that the variation of $\mathrm{dc}$ conductivity is rapid over a small temperature range. The calculated values of activation energies are found to be of the order of bismuth glasses [19]. The activation energy is found to be smaller 


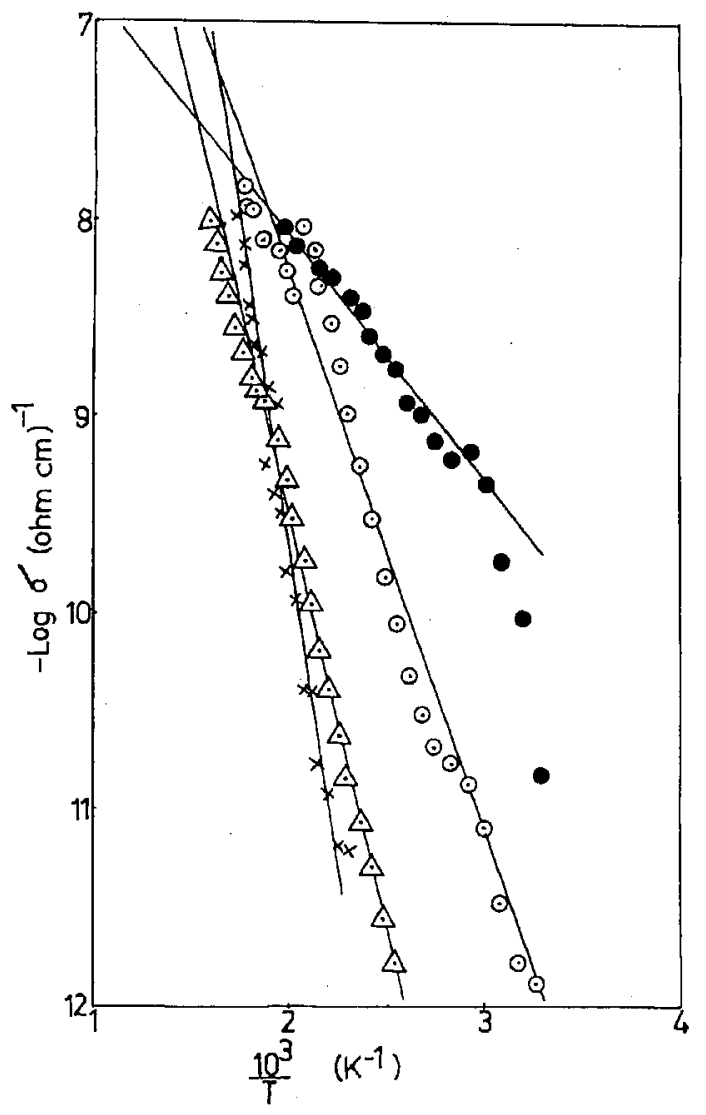

Fig. 1. Variation of dc electrical conductivity $\sigma$ with $1 / T: \bullet 80 \mathrm{CuO}-20 \mathrm{Bi}_{2} \mathrm{O}_{3}$, $\bigcirc 70 \mathrm{CuO}-30 \mathrm{Bi}_{2} \mathrm{O}_{3}, \triangle 60 \mathrm{CuO}-40 \mathrm{Bi}_{2} \mathrm{O}_{3}, \times 50 \mathrm{CuO}-50 \mathrm{Bi}_{2} \mathrm{O}_{3}$.

than $1 \mathrm{eV}$ for the contents of $\mathrm{CuO}$ more than $60 \mathrm{~mol} \%$ whereas for $50 \mathrm{~mol} \%$ of $\mathrm{CuO}$ it is more than $1 \mathrm{eV}$. This indicates that the pellets having in composition more than $60 \mathrm{~mol} \%$ of $\mathrm{CuO}$ exhibit predominant electronic conduction, whereas the pellet with $50 \mathrm{~mol} \% \mathrm{CuO}$ exhibits predominant ionic conduction [20]. Elliot [13] has discussed the phenomena of electrical conduction, on the basis of Eq. (2). According to him, when ionic motion occurs by filled enhanced thermally activated hopping between equivalent sites in the lattice, then the expression becomes valid. Hence the plot of $-\log (\sigma T)$ versus $1 / T$ is linear, if ionic conduction is dominant. A similar fact is observed in the pellets studied here (Fig. 2). It is worthwhile to mention here that the nature of electrical conduction mechanism (electronic or ionic) can only be decided if the plot of $-\log (\sigma T)$ and the activation energy are taken into account simultaneously.

The method of activation energy is counter check for the decision of the electrical conduction mechanism. Thus there are two categories.

1. If the plot of $-\log (\sigma T)$ versus $1 / T$ is non-linear and the value of acti- 


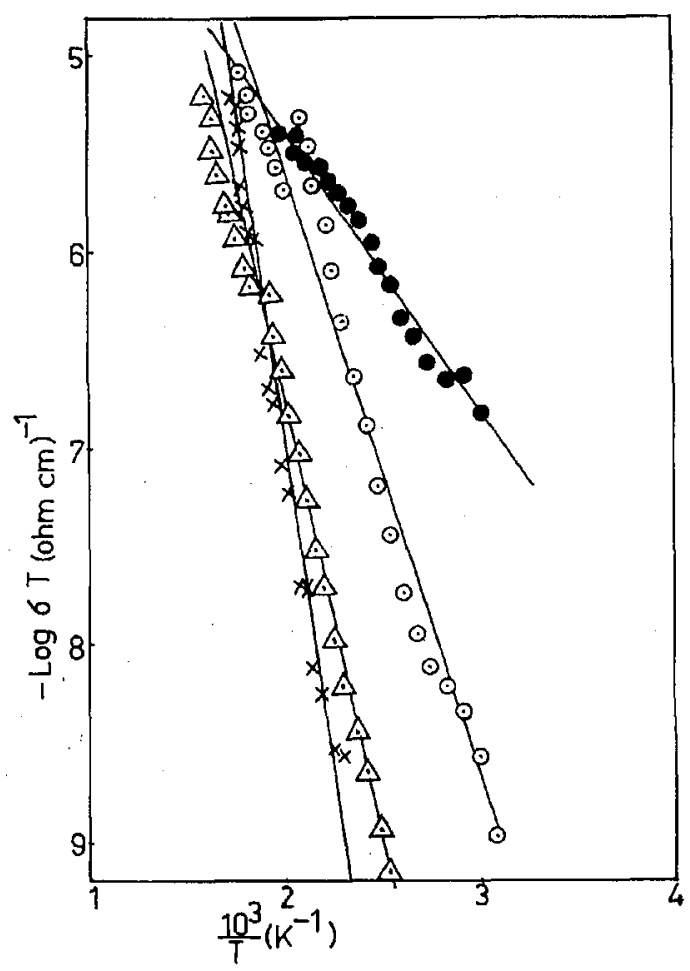

Fig. 2. Plot of $-\log (\sigma T)$ against $1 / T: \bullet 80 \mathrm{CuO}-20 \mathrm{Bi}_{2} \mathrm{O}_{3}, \bigcirc 70 \mathrm{CuO}-30 \mathrm{Bi}_{2} \mathrm{O}_{3}$, $\triangle 60 \mathrm{CuO}-40 \mathrm{Bi}_{2} \mathrm{O}_{3}, \times 50 \mathrm{CuO}-50 \mathrm{Bi}_{2} \mathrm{O}_{3}$.

vation energy is found to be smaller than $1 \mathrm{eV}$, then it indicates that there is a predominance of electronic conduction.

2. If the plot of the $-\log (\sigma T)$ versus $1 / T$ is linear, it means that Eq. (2) is valid and the value of activation energy is more than $1 \mathrm{eV}$, then it indicates that there is a predominance of ionic conduction. The forgoing discussion was about electrical conduction.

The plot of activation energy $(W)$ against content of $\mathrm{CuO}$ (mol\%) (Fig. 3) shows that the activation energy gradually decreases with increase in concentration of $\mathrm{CuO}$.

The hopping conduction of electrons/ions is discussed with the help of method suggested by Sayer et al. [17] and Murawaski et al. [18]. The validity of Eq. (10) is checked. Therefore $-\log \sigma$ is plotted against activation energy $(W)$ at fixed temperature (503 K) (Fig. 4). This indicates non-adiabatic hopping conduction of electrons/ions and hence is not mainly controlled by activation energy. This plot shows linear nature which gives the slope equal to $1 / k T$. Thus the temperature $T[\mathrm{~K}]$ is estimated. The estimated value of temperature $(10580 \mathrm{~K})$ does not fairly agree with the chosen fixed temperature. This indicates non-adiabatic hopping conduction of electrons/ions and hence is not mainly controlled by activation energy. 


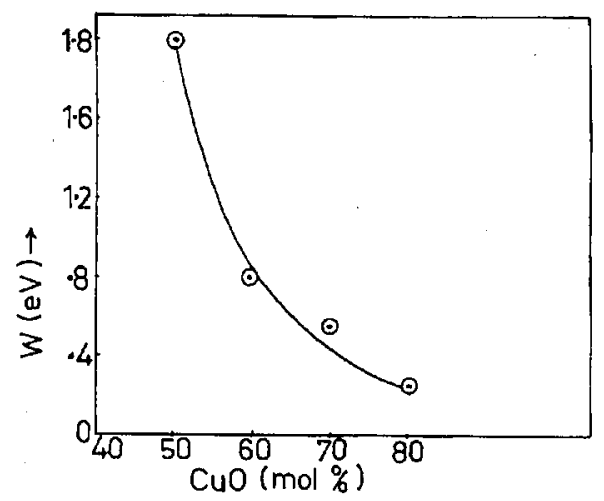

Fig. 3. Variation of activation energy $(W)$ with composition $\mathrm{CuO}(\mathrm{mol} \%)$.

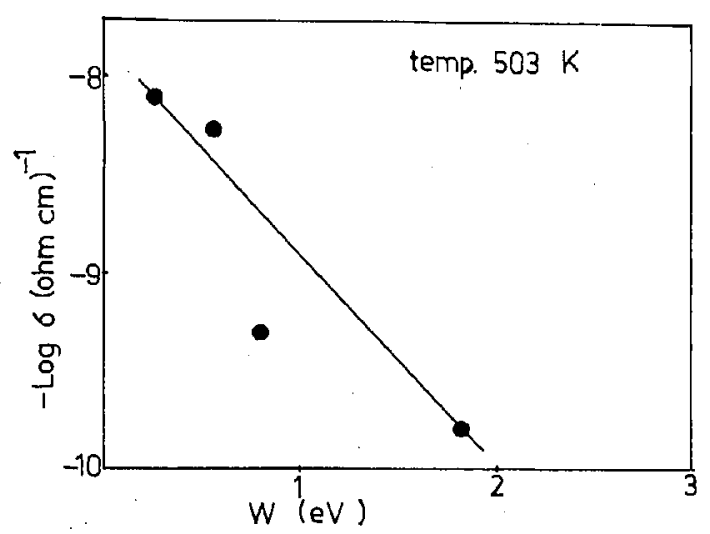

Fig. 4. Plot of $-\log \sigma$ versus activation energy $(W)$ at fixed temperature $(503 \mathrm{~K})$.

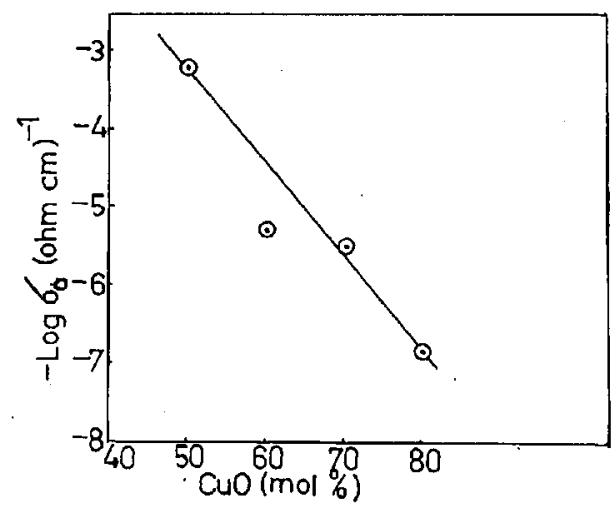

Fig. 5. Plot of pre-exponential factor $\left(-\log \sigma_{0}\right)$ versus composition $\mathrm{CuO}(\mathrm{mol} \%)$. 


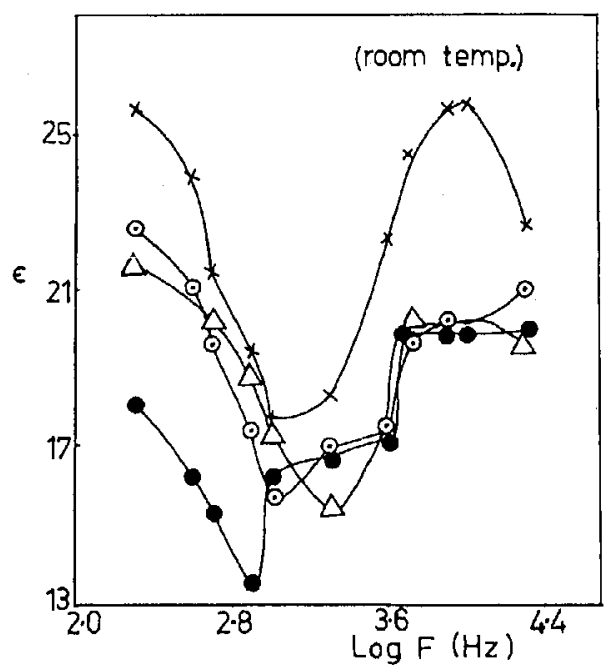

Fig. 6. Variation of a dielectric constant $\varepsilon$ with frequency $(f):-80 \mathrm{CuO}-20 \mathrm{Bi}_{2} \mathrm{O}_{3}$, $\bigcirc 70 \mathrm{CuO}-30 \mathrm{Bi}_{2} \mathrm{O}_{3}, \triangle 60 \mathrm{CuO}-40 \mathrm{Bi}_{2} \mathrm{O}_{3}, \times 50 \mathrm{CuO}-50 \mathrm{Bi}_{2} \mathrm{O}_{3}$.

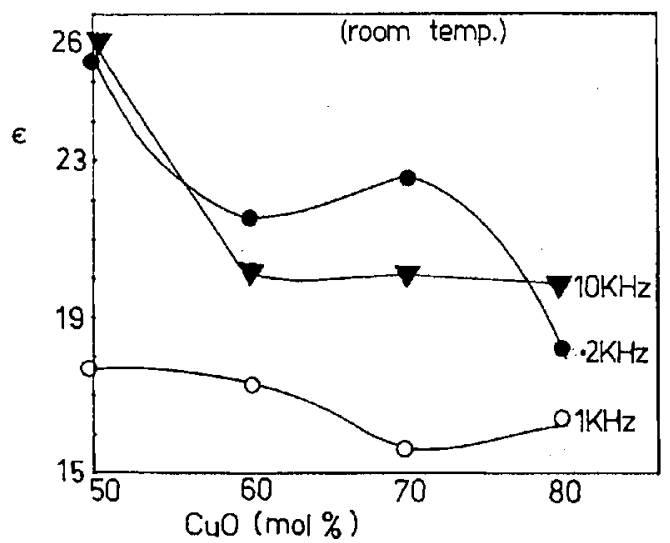

Fig. 7. Variation of dielectric constant $\varepsilon$ with $\mathrm{CuO}$ (mol\%) at room temperature $(303 \mathrm{~K}): \bigcirc 1 \mathrm{kHz}$ frequency, $\bullet 0.2 \mathrm{kHz}$ frequency, full $\nabla 10 \mathrm{kHz}$ frequency.

The intercept of plot of $-\log \sigma$ versus $1 / T$ gives a value of $-\log \sigma_{0}$. The plot of $-\log \sigma_{0}$ versus content of $\mathrm{CuO}$ (mol\%) (Fig. 5) shows that the pre-exponential factor linearly decreases with increase in content of $\mathrm{CuO}(\mathrm{mol} \%)$.

The variation of dielectric constant $(\varepsilon)$ with frequency $(f)$ (Fig. 6) shows zigzag nature and the dip around $1 \mathrm{kHz}$ while a pellet having $60 \mathrm{~mol} \% \mathrm{CuO}$ shows a dip at $2 \mathrm{kHz}$. This wobbling nature of dielectric constant may be due to the relaxation effects.

The plot of dielectric constant versus content of $\mathrm{CuO}(\mathrm{mol} \%)$ at three dif- 
ferent frequencies $0.2 \mathrm{kHz}, 1 \mathrm{kHz}$ and $10 \mathrm{kHz}$ (Fig. 7) shows that the variation of dielectric constant $\varepsilon$ with content of $\mathrm{CuO}$ (mol\%) is not systematic. The value of dielectric constant is found to be greater for $50 \mathrm{CuO}(\mathrm{mol} \%)$ pellet than for 60 , 70 and $80 \mathrm{CuO}(\mathrm{mol} \%)$.

\section{Conclusion}

The variation of $-\log \sigma$ versus $1 / T$ is linear as observed in the case of many semiconducting glasses. The mixed type of electrical conduction (ionic as well as electronic) is observed from activation energy, but it can be concluded that the charge carriers involved in the process of electrical conduction are mainly ions as the plot of $-\log (\sigma T)$ versus $1 / T$ is linear. The determination of charge carriers involved in the process of hopping conduction is supported by activation energy.

The non-adiabatic hopping conduction by ions is observed, suggesting a small influence of activation energy on dc conductivity. Activation energy is found to be temperature independent and depends on composition only.

The dielectric constant shows zigzag nature which depends on frequency as well as on $\mathrm{CuO}$ content (mol\%). The dipole relaxation phenomena are observed.

\section{Acknowledgment}

Thanks are due to Dr. V.S. Deogaonkar Head, Physics Department, Shri Shivaji Science College, Amravati and Principal Shri B.M. Thakare, B.N. College of Engineering, Pusad, for the necessary help rendered during the course of this work. We are also thankful to Prof. Bagade, Head of Physics Department, and Dr. Padhye, Principal, both from Govt. Vidarbha Mahavidyalaya, Amravati, for providing laboratory facilities.

\section{References}

[1] E.P. Denton, H. Rawson, J.E. Stanworth, Nature 173, 1030 (1954).

[2] L. Murawski, C.H. Chung, J.D. Mackenzie, Non-Cryst. Solids 32, 91 (1979).

[3] D. Chakravorty, C.S. Murthy, J. Phys. D 81, 162 (1975).

[4] I.G. Austin, N.F. Mott, Adv. Phys. 18, 4 (1969).

[5] A. Ghosh, B.K. Chauduri, Indian J. Phys. A 58, 62 (1984).

[6] B. Singh, P.S. Tarsikka, Indian J. Pure Appl. Phys. 27, 290 (1989).

[7] D.K. Burghate, W.J. Gawande, S.G. Motke, S.V. Pakade, S.P. Yawale, Indian J. Phys. A 68, 141 (1994).

[8] W.J. Gawande, D.K. Burghate, S.G. Motke, S.V. Pakade, S.P. Yawale, Indian J. Phys., to be published.

[9] S.G. Motke, D.K. Bhurghate, W.J. Gawande, S.V. Pakade, S.P. Yawale, Indian J. Mater. Sci. Eng., 1994, to be published.

[10] V.G. Kher, C.S. Adgaonkar, Indian J. Pure Appl. Phys. 10, 902 (1972).

[11] S.P. Yawale, Ph.D. Thesis, Amravati University, Amravati 1992.

[12] J.M. Stevels, Handbuch der Physik, Vol. 20, Springer Verlag, Berlin 1957, p. 573. 
[13] S.R. Elliot, Physics of Amorphous Materials, Longman, New York 1984, p. 226.

[14] N.F. Mott, J. Non-Cryst. Solids 1, 1 (1968).

[15] T. Holstein, Ann. Phys. 8, 343 (1959).

[16] D. Friedman, T. Holstein, Ann. Phys. 21, 494 (1963).

[17] M. Sayer, A. Mansingh, Phys. Rev. B 6, 4626 (1972).

[18] L. Murawaski, C.H. Chung, J.D. Mackenzie, J. Non-Cryst. Solids 32, 91 (1979).

[19] A.R. Kulkarni, H.S. Maiti, A. Paul, Bull. Mater. Sci. 6, 201 (1984).

[20] N.A. Karimi, D. Gupta, in: The Current Trends in the Physics of Materials, Ed. M. Yussovff, World Scientific, Singapore 1987, p. 201. 